\title{
PENERAPAN METODE FORWARD CHAINING UNTUK MENDIAGNOSA KEKURANGAN VITAMIN PADA MANUSIA (APOTIK SARI WARAS)
}

\author{
${ }^{1}$ Ade Indriani ${ }^{2}$ Budi Sutomo S.Kom,M.Ti ${ }^{3}$ M.Adie Syaputra S.Kom,M.Ti \\ ${ }^{1}$ Ade Indriani, STMIK Dharma Wacana, adeindriani460@gmail.Com \\ ${ }^{2}$ Budi Sutomo, STMIK Dharma Wacana, budi.Atmel@gmail.Com \\ ${ }^{3}$ M.Adie Syaputra, STMIK Dharma Wacana, m4adie@gmail.Com
}

\begin{abstract}
Abstrak
Kebutuhan akan informasi di era modern ini dituntut cepat dan tepat, salah satunya dalam bidang kesehatan dalam penelitian ini penulis akan menerapkan Metode forward chaining untuk mendiagnosa kekurangan vitamin pada manusia metode ini menganalisis proses pertanyaan (faktafakta) dengan gejala-gejala yang akan menyeleksi solusi terbaik dari sejumlah solusi, dalam hal ini solusi yang dimaksud adalah vitamin yang dibutuhkan oleh tubuh berdasarkan faktor yang ditentukan. kekurangan vitamin dalam sistem pakar ini terdiri dari vitamin $A$ dan $B$ (B1,B2,B3,B5,B6,B12),C,D,E serta $K$. Dengan adanya sistem pakar berbasis website ini, bisa mempermudah masyarakat dalam mendapatkan pelayanan informasi diagnosa kekurangan vitamin pada tubuh untuk pencegahan awal sebelum orang datang ke dokter umum maupun apoteker karena konsultasi menggunakan sistem pakar dapat dilakukan kapan dan dimana saja,serta lebih efisien waktu tanpa harus berkunjung ke apotek.
\end{abstract}

\section{Kata kunci: Kekurangan vitamin, Forward chaining, Website}

\section{Pendahuluan}

Menurut peraturan menteri kesehatan Republik Indonesia No 9 tahun 2017 tentang apotek menjelaskan Apotek adalah suatu sarana pelayanan kefarmasian tempat dilakukan praktik kefarmasian oleh apoteker dan memiliki tujuan untuk meningkatkan kualitas pelayanan, memberi perlindungan pasien dan masyarakat.

Apotek Sari Waras adalah apotek yang terletak di Kota Metro yang menyediakan obatobatan dan vitamin serta memiliki layanan dokter umum maupun apoteker. Saat ini untuk berkonsultasi dengan dokter umum maupun apoteker di apotek Sari Waras Kota Metro pasien harus berkunjung ke apotek, untuk itu dalam rangka meningkatkan kualitas pelayanan kesehatan kepada masyarakat dibutuhkan sebuah sistem pakar yang dapat menangani konsultasi layaknya dokter umum ataupun apoteker sehingga pasien dapat berkonsultasi dari mana saja tanpa harus berkunjung ke apotek.

Perancangan sistem pakar mendiagnosa penyakit kekurangan vitamin pada tubuh dirancang untuk dapat menganalisa dan mencari solusi terhadap penyebab gejala yang terdapat pada penyakit daya tahan tubuh. Sistem pakar dirancang dengan menggunakan basis pengetahuan para pakar Dokter praktek umum apotik sari waras. Basis pengetahuan vitamin berupa solusi yang terdapat pada daya tahan tubuh serta gejala-gejala yang mungkin timbul ketika penderita menderita kekurangan vitamin.

Sistem pakar diagnosa kekurangan vitamin pada tubuh dapat digunakan oleh pasien dalam mendiagnosa kekurangan vitamin pada tubuh berdasarkan kaidah mesin inferensi Forward Chaining, Forward chaining merupakan suatu stategi pengambilan keputusan yang dimulai dari fakta menuju kesimpulan akhir.

Dengan adanya sistem pakar ini diharapkan para pengguna dapat mengoperasikan secara langsung aplikasi melalui web dengan menjawab pertanyaan yang diajukan oleh sistem berupa gejala yang diderita. Pertanyaan yang sesuai dengan basis pengetahuan maka sistem akan memberikan informasi penyakit dan solusi pengobatan terhadap kekurangan vitamin pada tubuh.

\section{Metode Penelitian}

Metode penelitian adalah sebuah cara dalam mengumpulkan data yang digunakan dalam menunjang kegiatan penelitian. Pada penelitian kali ini penulis melakukan serangkaian kegiatan yang digunakan untuk merancang bangun aplikasi yang berfungsi mendiagnosa kekurangan vitamin pada manusia dengan menerapkan metode forward chaining. 


\section{LogikaManual Metode Forward Chaining}

Analisa perancangan data-data basis pengetahuan vitamin dan gejala klinis pada tubuh secara lengkap dapat dilihat pada pembahasan berikut ini :

\section{VITAMIN A}

Gejala klinisnya :

1. Apakah anda mengalami rabun senja ?

2. Apakah penglihatan mata anda terasa kabur ?

3. Apakah mata anda seperti menampakkan bayang-bayang?

\section{VITAMIN B1}

Gejala klinisnya :

1. Apakah anda merasa cepat lelah ?

2. Apakah nafsu makan anda berkurang?

VITAMIN B2

Gejala klinisnya :

1. Apakah anda mengalami bibir pecah-pecah?

2. Apakah anda tidak tahan terhadap cahaya matahari ?

VITAMIN B3

Gejala klinisnya :

1. Apakah anda mengalami gangguan pencernaan ( lambung, usus, perut ) ?

2. Apakah anda mengalami diare ?

3. Apakah anda mengalami mual dan muntah-muntah ?

VITAMIN B5

Gejala klinisnya :

1. Apakah anda mengalami sakit kepala ?

2. Apakah anda mengalami sulit tidur ?

3. Apakah anda merasakan kram dan kesemutan pada lengan, betis, telapak tangan?

VITAMIN B6

Gejala klinisnya :

1. Apakah daya tahan tubuh anda menurun?

2. Apakah anda mudah sakit?

VITAMIN B12

Gejalaklinisnya :

1. Apakahandamerasalemas ?

2. Apakah anda mengalami kurang darah atau anemia?

VITAMIN C

Gejala klinisnya :

1. Apakah anda mengalami sariawan ?

2. Apakah anda mengalami gusi berdarah?

\section{VITAMIN D}

Gejala klinisnya :

1. Apakah anda mengalami nyeri otot?

2. Apakah anda mengalami nyeri punggung?

3. Apakah anda mengalami nyeri pada tulang?
4. Apakah anda mengalami kerusakan pada gigi ?

VITAMIN E

Gejala klinisnya :

1. Apakah kulit anda kering ?

2. Apakah kulit anda bersisik ?

3. Apakah kulit anda mengalami pecah-pecah $?$

VITAMIN K

Gejala klinisnya :

1. Apakah anda mengalami pendarahan pada tubuh seperti darah keluar dari hidung ?

2. Apakah menstruasi anda mengalami pendarahan berlebihan?

\section{Tabel Rule Metode Forward Chaining}

\begin{tabular}{|c|c|c|c|}
\hline Rule & & IF & THEN \\
\hline \multirow{3}{*}{1} & G1 & $\begin{array}{l}\text { Apakah anda mengalarni } \\
\text { rabun senja? }\end{array}$ & \multirow{3}{*}{$\begin{array}{l}\text { KEKURANGAN } \\
\text { VITAMIN A }\end{array}$} \\
\hline & G2 & $\begin{array}{l}\text { Apakah penghihatan } \\
\text { mata anda terasa kabur? }\end{array}$ & \\
\hline & G3 & $\begin{array}{l}\text { Apakahmata anda } \\
\text { sepertimenampakkan } \\
\text { bayang-bayang? }\end{array}$ & \\
\hline \multirow{2}{*}{2} & G4 & $\begin{array}{l}\text { Apakah anda merasa } \\
\text { cepat lelah? }\end{array}$ & \multirow{2}{*}{$\begin{array}{c}\text { KEKURANGAN } \\
\text { VTTAMIN B1 }\end{array}$} \\
\hline & G5 & $\begin{array}{l}\text { Apakah nafsumakan } \\
\text { anda berkurang? }\end{array}$ & \\
\hline \multirow[b]{2}{*}{3} & G6 & $\begin{array}{l}\text { Apakah anda mengalami } \\
\text { bibir pecah-pecah? }\end{array}$ & \multirow[b]{2}{*}{$\begin{array}{l}\text { KEKURANGAN } \\
\text { VTTAMINB2 }\end{array}$} \\
\hline & G7 & $\begin{array}{l}\text { Apakah anda tidaktahan } \\
\text { terhadap cahaya } \\
\text { matahan? }\end{array}$ & \\
\hline \multirow{3}{*}{4} & G8 & $\begin{array}{l}\text { Apakah anda mengalami } \\
\text { gangguan pencemaan ( } \\
\text { lambung, usus, perut)? }\end{array}$ & \multirow{3}{*}{$\begin{array}{l}\text { KEKURANGAN } \\
\text { VTTAMIN B3 }\end{array}$} \\
\hline & G9 & $\begin{array}{l}\text { Apakah anda mengalam } \\
\text { diare? }\end{array}$ & \\
\hline & G10 & $\begin{array}{l}\text { Apakah anda menglarri } \\
\text { mual dan murtah- } \\
\text { muntah? }\end{array}$ & \\
\hline \multirow[b]{3}{*}{5} & G11 & $\begin{array}{l}\text { Apakah anda mengalami } \\
\text { sakit kepala? }\end{array}$ & \multirow{3}{*}{$\begin{array}{l}\text { KEKURANGAN } \\
\text { VITAMIN B5 }\end{array}$} \\
\hline & G12 & $\begin{array}{l}\text { Apakah anda mengalarmi } \\
\text { sulit tidur? }\end{array}$ & \\
\hline & G13 & $\begin{array}{l}\text { Apakah anda merasakan } \\
\text { kram dankesemitan } \\
\text { pada lengan, betis, } \\
\text { telapaktangan? }\end{array}$ & \\
\hline \multirow{2}{*}{6} & G14 & $\begin{array}{l}\text { Apakah daya tahan } \\
\text { tubuh andamemun? }\end{array}$ & \multirow{2}{*}{$\begin{array}{l}\text { KEKURANGAN } \\
\text { VITAMIN B6 }\end{array}$} \\
\hline & G15 & $\begin{array}{l}\text { Apakah anda mudah } \\
\text { sakit? }\end{array}$ & \\
\hline \multirow[b]{2}{*}{7} & G16 & $\begin{array}{l}\text { Apakah anda merasa } \\
\text { lemas? }\end{array}$ & \multirow{2}{*}{$\begin{array}{l}\text { KEKURANGAN } \\
\text { VITAMIN B12 }\end{array}$} \\
\hline & G17 & $\begin{array}{l}\text { Apakah anda mengalami } \\
\text { kurang darah atau } \\
\text { anemia? }\end{array}$ & \\
\hline
\end{tabular}




\begin{tabular}{|c|c|c|c|}
\hline \multirow{2}{*}{8} & G18 & $\begin{array}{l}\text { Apakah anda mengalami } \\
\text { sariawan? }\end{array}$ & \multirow{2}{*}{$\begin{array}{l}\text { KEKURANGAN } \\
\text { VITAMIN C }\end{array}$} \\
\hline & G19 & $\begin{array}{l}\text { Apakah anda mengalami } \\
\text { gusi berdarah? }\end{array}$ & \\
\hline \multirow{4}{*}{9} & G20 & $\begin{array}{l}\text { Apakah anda mengalami } \\
\text { nyeri otot? }\end{array}$ & \multirow{4}{*}{$\begin{array}{l}\text { KEKURANGAN } \\
\text { VITAMIN D }\end{array}$} \\
\hline & G21 & $\begin{array}{l}\text { Apakah anda mengalami } \\
\text { nyeri punggung? }\end{array}$ & \\
\hline & G22 & $\begin{array}{l}\text { Apakah anda mengalami } \\
\text { nyeri pada tulang? }\end{array}$ & \\
\hline & G23 & $\begin{array}{l}\text { Apakah anda mengalami } \\
\text { kerusakan pada } \\
\text { gigi? }\end{array}$ & \\
\hline \multirow{3}{*}{10} & G24 & Apakah kulit anda kering? & \multirow{3}{*}{$\begin{array}{l}\text { KEKURANGAN } \\
\text { VITAMIN E }\end{array}$} \\
\hline & G25 & $\begin{array}{l}\text { Apakah kulit anda bersisik } \\
\text { ? }\end{array}$ & \\
\hline & G26 & $\begin{array}{l}\text { Apakah kulit anda } \\
\text { mengalamipecah-pecah? }\end{array}$ & \\
\hline \multirow[t]{2}{*}{11} & G27 & $\begin{array}{l}\text { Apakah anda mengalami } \\
\text { pendarahan pada tubuh } \\
\text { seperti darah keluar dari } \\
\text { hidung? }\end{array}$ & \multirow{2}{*}{$\begin{array}{l}\text { KEKURANGAN } \\
\text { VITAMIN K }\end{array}$} \\
\hline & G28 & $\begin{array}{l}\text { Apakah menstruasi anda } \\
\text { mengalami pendarahan } \\
\text { berlebihan? }\end{array}$ & \\
\hline
\end{tabular}

\section{Diagram Pohon keputusan}

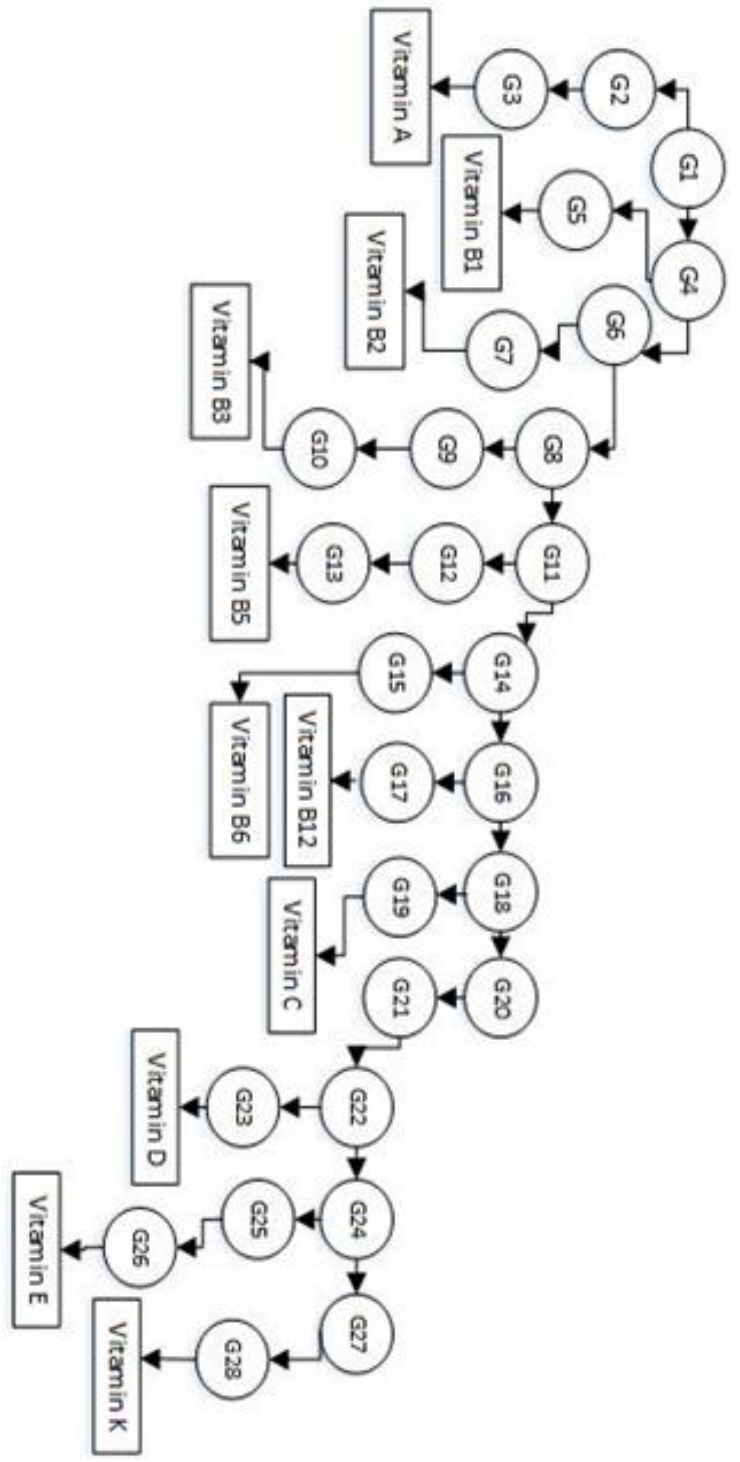

\section{Hasil dan pembahasan}

Tabel berikut ini merupakan contoh dari penelusuran metode forward chaining untuk sampel kekurangan vitamin A. Dimana akan diberikan pertanyaan berupa gejala - gejala dan sistem akan memberikan hasil diagnosa dari hasil konsultasi.

\begin{tabular}{|l|l|}
\hline NO & ATURAN ( RULE ) \\
\hline 1 & $\begin{array}{l}\text { IF anda mengalami rabun senja is } \\
\text { TRUE }\end{array}$ \\
\cline { 2 - 3 } & $\begin{array}{l}\text { AND penglihatan mata anda terasa } \\
\text { kabur is TRUE }\end{array}$ \\
\cline { 2 - 3 } & $\begin{array}{l}\text { AND Apakah mata anda seperti } \\
\text { menampakkan bayang - bayang ? }\end{array}$ \\
\cline { 2 - 2 } & THEN kekurangan vitamin A \\
\hline
\end{tabular}

Proses penelusuran forward chaining dapat dilihat sebagai berikut :

\section{IF G1 THEN G2}

2. IF G2 THEN G3

3. IF G3 THEN VITAMIN A: GOAL

Kekurangan vitamin A melalui proses 3 rule dimana penelusuran pertama itu dieksekusi apabila fakta cocok dengan aturan bagian IF pada bagian IF-THEN. Kemudian data tersebut menghasilkan fakta baru dibagian THEN yang akan disimpan ke database. Proses penelusuran dilakukan dari rule pertama dan tidak ada pengulangan eksekusi. Proses eksekusi akan berhenti apabila tidak ada lagi data yang sesuai dan akan mengeluarkan kesimpulan berdasarkan pencocokan fakta.

\section{Kesimpulan}

Dari hasil evaluasi sistem pakar ini, dapat disimpulkan bahwa aplikasi sistem pakar yang dibuat dengan menggunakan proses penelusuran maju Forward Chaining, mampu mengenali jenis kekurangan vitamin pada tubuh manusia, antara lain vitamin A, B1, B2, B3, B5, B6, B12, C, D, E dan K.

Dengan adanya sistem pakar ini, bisa mempermudah orang mendapatkan pelayanan informasi diagnosa kekurangan vitamin pada tubuh untuk pencegahan awal sebelum orang datang ke dokter spesialis, karena konsultasi menggunakan sistem pakar dapat dilakukan kapan dan dimana saja, serta lebih efisien waktu. 


\section{Daftar Pustaka}

DepKes, R. I. (2017). Peraturan Menteri Kesehatan Republik Indonesia Nomor 9 Tahun 2017 tentang Apotek.

Abdulloh, Rohi. 2016. Easy dan Simple Web Programming. Jakarta: Elex Media Komputindo.

Ause Labelllapansa1, Alex Timr Boyz2, 2016 Sistem Pakar Diagnosa Dini Defisiensi Vitamin Dan Mineral. JURNAL INFORMATIKA Vol. 10, No. 1, Jan 2016.

Irawan Jusak. (2019). PEGANGAN SISTEM PAKAR.Institut of Business and Informatics Stikom Surabaya. https://www.researchgate.net/publication / 334560020

Jacobson, I. M. (1992).Object-Oriented Software Engineering: A Use Case Driven Approach.

Lardinois (2015).Visual Studio Team Services.

Paul (2008).PengenalanChromecast, Chromebook, Chromebit, ChromeboxdanChromebase.

Riyanto (2015).Panduandasarpenggunaan XAMPP.

Sutarman, 2012."Buku Pengantar Teknologi Informasi"Jakarta:Bumi aksara.

Tim Dosen Dharma Wacana (2016). "Panduan Penulisan Skripsi dan Tugas Akhir". STMIK Dharma Wacana Metro. 